\title{
Assessing urban resilience
}

\author{
C. E. Cloete \\ Department of Construction Economics, \\ University of Pretoria, South Africa
}

\begin{abstract}
Investigation of the resilience of cities has become increasingly important in view of the various natural and man-made threats to the sustainability of urban complexes in which more than half the world's population lives.

The paper provides an overview of the pertinent concepts as well as the various approaches to the assessment of the resilience of cities. It elaborates on the concepts of complexity and dynamic systems and attempts to clarify the concept of resilience itself by analysing its characteristics and contrasting it with related concepts such as sustainability, resistance, equilibrium, stability, durability and robustness. It proposes that the essence of resilience is the ability of a system to absorb changes without a transition to a different state.

Keywords: resilience, systems, complexity, cities, sustainability.
\end{abstract}

\section{Introduction}

More than half the world's population is now urbanised [1]. The future welfare of billions of people is therefore closely coupled to the continued sustainability of cities [2].

The vulnerability of urban complexes to various natural and man-made threats has led to an increased concern about the survival of cities and mitigating measures to catastrophes that can threaten their survival. As stated by the World Bank [1:4]: "How a city is structured to manage its growth and vulnerabilities is critical."

An indication of the ability of a city to withstand shocks to its survival is given by the concept of resilience [3]. The concept of resilience suffers from imprecision of definition and conceptualisation, which hampers its use in academic discourse [4]. Resilience is, moreover, quite often confused with related concepts such as sustainability, adaptability, transformability, resistance, 
equilibrium, stability, durability and robustness. The meanings of these concepts as they relate to a city are therefore analyzed, with reference to the characteristics of a city as a complex, socio-economic system. Some implications for the methodology required to study urban resilience are briefly discussed.

\section{Cities as complex, dynamic systems}

A system can be defined as "A set of elements or parts that is coherently organized and interconnected in a pattern or structure that produces a characteristic set of behaviors, often classified as its "function" or "purpose." [5:188]

According to Weaver [6], cf. [7], systems could be classified as applicable to three kinds of problem: problems of simplicity, problems of disorganized complexity, and problems of organized complexity.

Jacobs [8] was the first to propose that these "problems of organized complexity" included cities - indeed that the city was the example par excellence of organized complexity.

In addition to being complex, social-economic systems are adaptive, as was realised by systems theorists more than 50 years ago - see e.g. [9-11]. Socialeconomic systems have the ability to change, i.e. their constituent agents constantly adapt to each other and to the external environment - see e.g. [3, 12].

Sanders [13] has summarised the characteristics of complex adaptive systems as follows:

1. "Diversity among the components; heterogeneous parts or "agents;" sources of novelty in the system. Includes some sort of natural selection processes within agent groups that ensure ongoing evolution, regeneration, and adaptation.

2. Nonlinear interactions; widespread information flow and feedback loops.

3. Self-organization; results from attractors in the system, and from adaptation to changes in the larger environment and other agents.

4. Local information processing; local interactions among autonomous agents. Typically agents "see" only their part of the system and act locally; no global control.

5. Emergence; exhibits unpredictable global behavior or patterns; spontaneous order emerges from local system interactions.

6. Adaptation; open and responsive to changes to the larger environment or context and to other agents in the system; continuously processing, learning, and incorporating new information; making boundaries hard to define.

7. Organization across multiple scales; agents in the system organized into groups or hierarchies of some sort, which influence how the system evolves over time.

8. Sensitivity to changes in initial conditions; small changes can create big results at some point in the future. 
9. Non-equilibrium; most interesting behavior/creativity found at the "edge of chaos;" healthy systems operate in a dynamic state somewhere between the extremes of order and disorder, making it easier for them to adapt to changing conditions.

10. Best understood by observing the behavior - activities, processes, adaptation - of the whole system over time; qualitative descriptions and understanding versus quantitative descriptions alone."

An even briefer (but in some respects more comprehensive) summary of the characteristics of complex adaptive systems was provided by Cilliers [14, 15], who also indicated the implications of these characteristics for the study of complex adaptive systems:

- $\quad$ Complex adaptive systems comprise many interacting dynamic elements or subsystems, connected together in irregular ways in an open context.

- $\quad$ They consist of nested systems that span a range of dimensions or scales.

- $\quad$ They are more than the sum of their parts - i.e. they show emergent properties that are not found in the properties of the individual parts.

- $\quad$ They have histories, with past behaviour and experience influencing current behaviour, allowing agents to learn from experience.

- Interactions between elements tend to be rich (i.e. each element influences and is influenced by a number of other elements), but primarily shortrange (i.e. mainly with immediate neighbours).

- The interactions between simpler elements allow self-organization into more complex structures.

- The connections or interactions between the elements of the system are nonlinear and contain feedback loops, which implies that small causes can have large results.

- The system operates far from equilibrium and exhibits hysteretic or irreversible behaviour - i.e. it may resist change up to a certain threshold point at which it flips irreversibly into a different state [17].

As pointed out by Du Plessis [17], 'Understanding ... complex, adaptive systems means that the important properties to study are those related to change and the system's ability to deal with change - for example, resilience, adaptability, transformability, connectivity and diversity."

The complex adaptive system is presently more commonly denoted as a multi-agent system [18]. The basic components of a complex adaptive system are called agents, which can be conceived as autonomous individual components that try to achieve some goal or value ("utility" or "fitness") by acting upon their environment. Agents can be persons, cells, artefacts or molecules [18]. Although agents typically only interact with a limited number of other agents in their local neighbourhood, these local interactions may result in consequences on a macro level. Such macro effects are emergent in the sense that they could not have been inferred from properties that govern the behaviour of the individual agents 
$[19,20]$. "Agents are intrinsically subjective and uncertain about the consequences of their actions, yet they generally manage to self-organize into an emergent, adaptive system. Thus, uncertainty and subjectivity should no longer be viewed negatively, as the loss of the absolute order of mechanicism, but positively, as factors of creativity, adaptation and evolution" [18].

Complexity is an emergent phenomenon that arises from interactions between the components of the system. In turn, an emergent property of complex humanenvironment relations is that of resilience. This concept reflects the tension between stasis and dynamism [16]. It refers to the factors that combine to build and sustain a system's identity [21]. This concept will be investigated in some detail in a later section.

Helbing [22:1]: emphasizes that "The commonality of complex systems is that they are characterized by a large number of interacting (mutually coupled) system elements ... These interactions are usually non-linear ... Typically, this implies a rich system behavior ... In particular, such systems tend to behave dynamic rather than static, and probabilistic rather than deterministic. As a consequence, complex systems can show surprising or even paradoxical behaviors. ... Moreover, complex systems are often hardly predictable and uncontrollable. "

It is apparent that cities are dynamic and complex socio-economic systems, exhibiting all the characteristics of such systems [23].

Application of the above characteristics of complexity to a city leads to the following observations [13].

1. Local, simple interactions create self-organizing global patterns of community.

2. The vitality of living cities emerges from the interactions created by multiple, connected, diverse centres of activity. (Cities usually form around some relatively stable attractor such as a geographic feature)

3. Aesthetic coherence is created by recognizing and incorporating the fractal qualities of people, place, and environment.

4. A living city frames our interactions with subtle visual connections among people, place, and environment.

5. A living city evolves within a larger context where emerging, new initial conditions will influence and shape its ongoing development.

\section{Sustainability}

The concept that sustainable development is "development that meets the needs if the present without compromising the ability of future generations to meet their needs" [24] is generally accepted.

Holling [25] suggests instead that sustainability is the capacity to create, test and maintain adaptive capability. This implies that sustainability requires both change and persistence.

Fiksel [26] proposes that for system design purposes the following definition of sustainability is useful: "A product, process, or service contributes to sustainability if it constrains environmental resource consumption and waste 
generation to an acceptable level, supports the satisfaction of important human needs, and provides enduring economic value to the business enterprise." Similarly, Newman [27] proposes that "A sustainable city is one that is reducing its ecological footprint (its resource consumption, land consumption and waste production) whilst simultaneously improving its quality of life (its health, housing, work opportunities and livability)." This definition implies that sustainability should be considered in the context of a larger set of problems that include questions of economic growth, social equity and local diversity.

\section{Resilience}

The quintessential characteristic of sustainability is resilience, i.e. the capacity of a system to absorb disturbances and reorganize while undergoing change so as to retain essentially the same function, structure, identity, and feedbacks

The Latin root of the term "resilience" refers to the ability of an entity or system to the power of recovery following a disturbance or disruption of some kind, i.e. its ability to recoil or rebound [5]. Following a proposal [28] that it could be a key aspect of the dynamics of spatial economic systems, this is the way in which the term is mostly used in systems theory (e.g. "Resilience: The ability of a system to recover from perturbation; the ability to restore or repair or bounce back after a change due to an outside force" [29:18]), and is applied in regional economics and urban applications, e.g. [30, 31] in spite, as Martin [5] points out, of the admittedly somewhat ambiguous interpretation of the term and the contentious application across the different sciences [32-34].

The lack of resilience is called brittleness [35].

Martin [5:6] points out that the use of the term in different disciplines suggests that at least three different but related interpretations: so-called 'engineering' resilience, 'ecological' resilience and 'adaptive' resilience.

The first of these interpretations - the so-called 'engineering' resilience, assumes a system to be in a state of equilibrium (or in a steady state) of before the shock [36-38]. The second definition - 'ecological' resilience - refers to the size of the shock that can be tolerated before a system is pushed beyond its elasticity threshold into a different form, function or position [25, 36, 38-40]. Some authors, however, use this definition to refer to the ability of the system, when pushed beyond its 'elasticity threshold', to quickly settle in a new stable static or dynamic configuration [41]. The third view of resilience is essentially an evolutionary one: driven by co-evolutionary interactions between its components, self-organizing behaviour occurs whereby its internal structure is rearranged spontaneously [42]. Given the viewpoint adopted above of considering the city as a complex, adaptive system, the latter interpretation is of particular interest and will be pursued in more detail below.

In the analysis of social-ecological system resilience, four key systems features are of special interest: latitude, precariousness, resistance and panarchy [43]. "Latitude refers to the capacity of a system to undergo change before recovery is 'difficult or impossible'. Resistance refers to the 'ease or difficulty' of changing the system. Precariousness concerns the definition of critical limits 
and thresholds of system function and behaviour. Panarchy is concerned with cross-scale interactions that influence system resilience positively or negatively" $[17,44]$.

The reaction of a system to a shock can be described in terms of four interrelated dimensions: "The first is that of resistance, that is the vulnerability or sensitivity of a regional economy to disturbances and disruptions, such as recessions. The second is that of the speed and extent of recovery from such a disruption. Of interest here is whether the speed and extent of recovery are determined by the degree of resistance to the shock in the first place. The third aspect concerns the extent to which the regional economy undergoes structural re-orientation and what implications such re-orientation has for the region's output, jobs and incomes. The fourth dimension concerns the degree of renewal or resumption of the growth path that characterised the regional economy prior to the shock. In addition, these different aspects or dimensions of regional economic resilience may interact in different ways, to produce different outcomes..." [5: 15].

The transformability of a system is the capacity to create a fundamentally new system when ecological, economic, or social (including political) conditions make the existing system untenable. This response to a crisis is a response that involves crossing thresholds, it entails substantial change and is resourceintensive [43].

Vulnerability denotes the propensity to suffer harm from exposure to external stresses and shocks.

Adaptability, on the other hand, “...can be said to be an emergent characteristic of a system that enables it to avoid, survive, or recover from a disruption." [35]. It is emergent because it is a property of the interaction between components, and not of the components themselves. The response of the system to a threat is to prevent the crossing of thresholds into different states [43].

Characteristics of resilient systems include diversity, efficiency, adaptability and cohesion [26]. In the case of a socio-economic system (like a city) "diversity" (the existence of multiple behaviours and forms) implies ethnic, cultural, institutional and political diversity, while "cohesion" (the existence of unifying forces or linkages) refers to a strong identity like a common culture (the individual, organizational, or national beliefs that govern our actions [35] or social cohesion. "Social cohesion within a neighborhood, which refers to harmonious interactions and mutual support among residents, is integral to the social sustainability of the neighborhood" [45].

Efficiency (cost-efficient means for human needs satisfaction) and adaptability (flexibility of institutions) are achieved by interelement cooperation, collaboration and/or communication. Adaptive governance recognizes cross-scale interactions and promote interaction across organizational levels [46]. The response to Hurricane Katrina, where little communication or cooperation occurred among government agencies is an example of the catastrophic results that can occur where the system fails the adaptability test. The rapid efficient and effective response of Japan to the March 11, 2011 
earthquake, tsunami and nuclear crisis is an example of the successful adaptability of a society to a disaster.

\section{Resilience and urban vulnerability}

The World Bank [1] expresses the importance of resilience of cities and the crucial role of human actors as follows: "The concept of resilience is central to the understanding of urban area vulnerability.... Resilience in social systems has the added human capacity to anticipate and plan for the future. Humans depend on resilience for survival. A resilient city is one that is able to sustain itself through its systems by dealing with issues and events that threaten, damage, or try to destroy it....There are three defining characteristics of resilience in humanecological systems: (a) the amount of disturbance a society can absorb and still remain within the state of the domain of attraction; (b) the degree to which the society is capable of self-organization or adjustment; and (c) the degree to which the society can build and increase the capacity for learning and adaptation."

Three aspects of resilience are involved in responses to disasters. Physical resilience refers to the ability of a city or community to rebuild its physical structure. Emotional resilience refers to the ability of individuals, families and communities to cope and heal from trauma. Cultural resilience signifies the perseverance of cultural practices and norms through events of great cultural trauma (i.e. the ability of customs, traditions, languages or religions to survive and evolve) [3].

\section{Ameliorating features}

Adaptive capacity is determined by, among others, the diversity in the system, (particularly the response diversity), the degree of connectedness within the system and the tightness of feedback [47].

The requirement of connectedness (as instantiated in networks) is highlighted by Helbing [22:10] "As the example of ecosystems shows, a networked system can have an astonishing degree of robustness without any central control. Robustness just requires the right interaction rules, which may be implemented, for example, by social norms, laws, technological measures etc., depending on the system. Properly chosen rules will lead to a self-regulation or self-control of the system, but improper specifications can lead to low performance or systemic instability."

A second contribution to the continued sustainability of a complex system is to have sufficient diversity in the system's components: "Complex, hierarchically organized systems (e.g., aircraft, nuclear plants) tend to have rigid operating parameters, are resistant to stress only within narrow boundaries, and may be vulnerable to small, unforeseen perturbations. Alternatively, distributed systems composed of independent yet interactive elements may deliver equivalent or better functionality with greater resilience" [26].

An analogy may be found in investment theory, where is it is widely acknowledged that diversification diminishes risk in an investment portfolio. 
Incorporation of efficient diversification in a portfolio limits the possibility of an event causing a catastrophic loss. In fact, if the elements (components) of the portfolio can be chosen to be inversely correlated, the counter-intuitive result that high returns can be achieved without increasing the risk is obtained $[49,50]$.

The concept of diversity itself is not unambiguous and is open to different interpretations. Three fundamental types of diversity constructs may be distinguished: separation, variety and disparity [51].

Helbing [22] speculates that social differentiation is a success principle promoting cooperation, and suggest that "The hypothesis to be tested is that local cultures are beneficial for the level of cooperation in a social system and that increasing spatial homogeneity would destroy the natural forces keeping a social system together. This would require strengthening other cooperation-enhancing mechanisms in order to stabilize the system."

This view is supported by Seymoar [52] who, in summarizing the major lessons learnt from responses to a wide variety of catastrophes, lists "Increase community and economic diversity (incorporate immigrants)" and "Develop or maintain a middle group (class)" as among the most valuable lessons - cf. [53, 54].

\section{Conclusion}

Various nuances in the meaning of the term "resilience" have been unravelled and the term has been distinguished from related terms. It is recommended that extreme care is taken when utilizing the related terms in discourse about the resilience of cities. In particular, it is suggested that the term should not be used when a change of state of a system occurs.

A second conclusion is that the resilience of any complex system (like a city) is determined by, among others, the degree of connectedness in the system and the diversity of its components.

\section{References}

[1] Prasad, Neeraj, Ranghieri, Federica, Shah Zoe Trohanis, Fatima, Kessler, Earl and Sinha, Ravi, Climate Resilient Cities. A Primer on Reducing Vulnerabilities to Disasters, The World Bank: Washington, D.C., 2009.

[2] Glaeser, Edward, Triumph of the City, Penguin: New York, 2011.

[3] Vale, L.J. and Campanella. T.J., (eds.) The Resilient City, Oxford University Press: New York, 2005.

[4] Hanley, N., Resilience in Social and Economic Systems: A Concept that Fails the Cost-Benefit Test? Environment and Development Economics, 3, pp. 244-249, 1998.

[5] Martin, Ron, Regional Economic Resilience, Hysteresis and Recessionary Shocks, Plenary Paper Presented at the Annual International Conference of the Regional Studies Association, Newcastle, pp. 1-40, 17-20 April, 2011.

[6] Weaver, W. Science and complexity. American Scientist, 36, pp. 536-44, 1948. 
[7] Rapoport, Anatol and Horvath, W. J., Thoughts on organization theory, General Systems, 4, pp. 87-91, 1959.

[8] Jacobs, Jane, The Death and Life of Great American Cities. Vintage Books, Random House: New York, 1992.

[9] Simon, Herbert A, The Architecture of Complexity, Proceedings of the American Philosophical Society, 106(6), pp. 467-482, Dec. 12, 1962.

[10] Buckley, W (ed.), Modern Systems research for the Behavioral Scientist. A Sourcebook, Aldine Publishing: Chicago, 1968.

[11] Kuhn, Alfred. The Logic of Social Systems. Jossey-Bass Publishers: San Francisco, 1974.

[12] Du Plessis, C., Understanding Cities as Social-ecological Systems, World Sustainable Building Conference - SB'08 , Melbourne, Australia, 21-25 September, 2008.

[13] Sanders, T. Irene, Complex Systems Thinking and New Urbanism, in New Urbanism and Beyond: Designing Cities for the Future. Tigran Haas (ed.), New York: Rizzoli, pp. 275-79, 2008.

[14] Cilliers, P., Complexity and Post-modernism: Understanding complex systems, Routledge: London, p.45, 2008.

[15] Cilliers, P. Complexity theory as a general framework for sustainability science, in Burns, Michael \& Weaver, Alex, (eds.), Exploring Sustainability Science. A Southern African Perspective, Sun Press: Stellenbosch, pp. 3957, 2008.

[16] Burns, Michael \& Weaver, Alex, (eds.), Exploring Sustainability Science. A Southern African Perspective, Sun Press: Stellenbosch, 2008.

[17] Du Plessis, Chrisna, A conceptual framework for understanding socialecological systems, in Burns, Michael \& Weaver, Alex, (eds.), Exploring Sustainability Science. A Southern African Perspective, Sun Press: Stellenbosch, pp. 59-90, 2008.

[18] Heylighen F., Cilliers, P. and Gershenson, C., Complexity and Philosophy, in: Jan Bogg and Robert Geyer (eds.), Complexity, Science and Society, Radcliffe Publishing: Oxford, 2007.

[19] Holland, John H., Emergence: From chaos to order, Oxford University Press: Oxford, 1998.

[20] Morowitz, Harold, J., The Emergence of Everything, Oxford University Press: Oxford. 2002.

[21] Sendzimir, J., Critical examination of resilience theories and measures. Report to CAVES project. Deliverable 6, EU 6th Framework, 2006.

[22] Helbing, Dirk. Systemic Risks in Society and Economics. Working paper 09-12-044, Santa Fe Institute. Accessed on 20 April 2012 at http://www.santafe.edu/media/workingpapers/09-12-044.pdf

[23] Portugali, J, Complexity, Cognition and the City, Springer: (Preface), 2011.

[24] World Commission on Environment and Development, Our Common Future, Oxford University Press: Oxford, 1987.

[25] Holling, C.S. Understanding the Complexity of Economic, Ecological and Social Systems, Ecosystems, 4, pp. 390-405, 2001. 
[26] Fiksel, J. Designing Resilient, Sustainable Systems, Environmental Science and Technology 37(23): 5330, 2003

[27] Newman, P. (with Timothy Beatley and Heather Boyer) Resilient Cities: Responding to peak oil and climate change, Island Press: Washington, 2009.

[28] Reggiani, A., de Graff, T. and Nijkamp, P., Resilience: An Evolutionary Approach to Spatial Economic Systems, Networks and Spatial Economics, 2, pp. 211-229, 2002.

[29] Meadows, Donella H. Thinking in Systems. Vermont: White River junction: Chelsea Green Publishing, 2008.

[30] Foster, K. A., A Case Study Approach to Understanding Regional Resilience, Working Paper 2007-08, Institute of Urban and Regional Development, Berkeley, 2007.

[31] Hill, E. W., Wial, H. and Wolman, H., Exploring Regional Economic Resilience, Working Paper 2008-04, Institute of Urban and Regional Development, Berkeley, 2008.

[32] Hassink, R., Regional Resilience: A promising Concept to Explain Differences in Regional Economic Adaptability? Cambridge Journal of Regions, Economy and Society, 3(1), pp. 45-58, 2010.

[33] Hudson, R., Resilient Regions in an Uncertain World: Wishful Thinking or Practical Reality? Cambridge Journal of Regions, Economy and Society, 3(1), pp. 11-26, 2010.

[34] Pike, A., Dawley, S. and Tomaney, J. Resilience, Adaptation and Adaptability, Cambridge Journal of Regions, Economy and Society, 3(1), pp. 59-70, 2010.

[35] Jackson, Scott, Architecting Resilient Systems: Accident Avoidance and Survival and Recovery from Disruptions, John Wiley \& Sons, p. 7, 2010.

[36] Holling, C. S., Resilience and Stability of Ecological Systems, Annual Review of Ecology and Systematics, 4, pp. 1-23, 1973.

[37] Pimm, S.L., The Complexity and Stability of Economic Systems, Nature, 307, pp. 321-326, 1984.

[38] Walker, B., Gunderson, L., Kinzig, A., Folke, C., Carpenter, S. and Schultz, L. A Handful of Heuristics and Some Propositions for Understanding Resilience in Socio-Ecological Systems, Ecology and Society, 11, 2006. (http://www.ecologyandsociety.org/vol11/iss1/art13/)

[39] Holling, C. S., Engineering Resilience Versus Ecological Resilience in Schulze, P. (ed.) Engineering within Ecological Constraints, Washington, D.C.: National Academy Press, pp. 31-44, 1996.

[40] McGlade, J., Murray, R., Baldwin, J., Ridgway, K. and Winder, B., Industrial Resilience and Decline: A Co-evolutionary Framework, in Garnsey, E. and McGlade, J. (eds.), Complexity and Co-Evolution: Continuity and Change in Socio-economic Systems, Cheltenham: Edward Elgar, pp. 147-176, 2006.

[41] Romer, R., Advanced Macroeconomics, New York: McGraw Hill, 2001. 
[42] Martin, R.L. and Sunley, P.J., Complexity Thinking and Evolutionary Economic Geography, Journal of Economic Geography, 7(4), pp. 16-45, 2007.

[43] Walker, B., Holling, C.S., Carpenter, S. R. and Kinzig, A. Resilience, adaptability and transformability in social-ecological systems. Ecology and Society 9(2) 2004:5.

[44] Peter, C., Complexity based modelling for sustainability and resilience of social-ecological systems, in Burns, Michael \& Weaver, Alex, (eds.), Exploring Sustainability Science. A Southern African Perspective, Sun Press: Stellenbosch, pp. 471-506, 2008.

[45] Chau-kiu Cheung and Kwan-kwok Leung. Neighborhood homogeneity and cohesion in sustainable community development. Habitat International 35: 564-572, 2011.

[46] Resilience Alliance. 2010. Assessing resilience in social-ecological systems: Workbook for practitioners. Version 2.0. Online: http://www.resalliance.org/3871.php

[47] Walker, B.H. and Salt, D., Resilience Thinking. Sustaining Ecosystems and People in a Changing World. Washington D.C.: Island Press, 2006.

[48] Helbing, D., Yu, W., and Rauhut, H., Self-organization and emergence in social systems. Modeling the coevolution of social environments and cooperative behavior.

[49] Cloete, C. E., Property Investment in South Africa (2nd ed.), South African Property Education Trust: Sandton, 2005.

[50] Pyhrr, S. A., Cooper, J. R., Wofford, L. E., Kaplin, S. D. and Lapides, P. D., Real Estate Investment. Strategy, Analysis, Decisions (2nd ed.). Wiley: New York, 1989.

[51] Harrison, David A. and Klein, Katherine J., What's the difference? Diversity constructs as separation, variety, or disparity in organizations. Academy of Management Review 2007.

[52] Seymoar, Nola-Kate, Strengthening community resilience. Paper written for the Province of British Columbia, Community, Aboriginal and Women's Services, with support from Western Economic Diversification Canada and the International Centre for Sustainable Cities Abridged version Oct 2007.

[53] Buck N., Social cohesion in cities. In Buck, N, Gordon, I, Harding, A and Turok, I (eds.), Changing cities: Rethinking urban competitiveness, cohesion and governance. Palgrave MacMillan: New York (USA), pp. 44$61,2005$. 